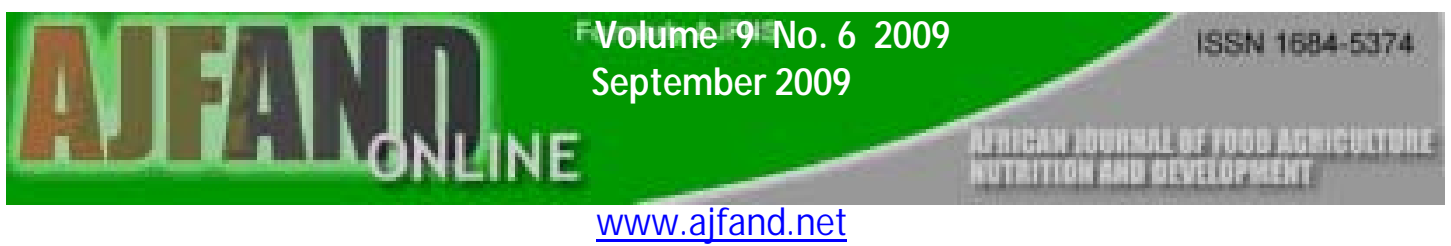

'Public Domain material, reproduced from Journal of Nutrition Education and Behavior 2007;39(6):327334.

\title{
Women's NutriBusiness Cooperatives in Kenya: An Integrated Strategy for Sustaining Rural Livelihoods
}

Maretzki $\mathrm{AN}^{* 1}$

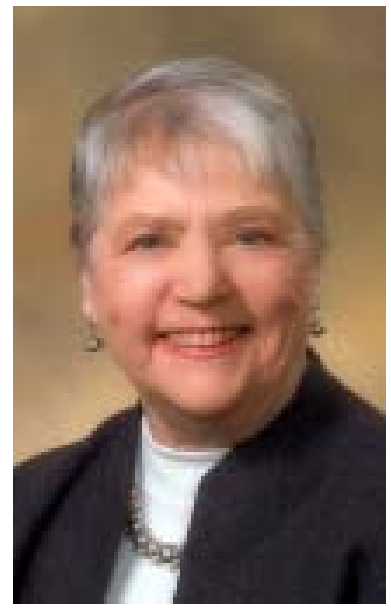

Maretzki Audrey

*Corresponding author email: anm1@psu.edu

${ }^{1}$ Emeritus Professor of Food Science and Nutrition, Department of Food Science, The Pennsylvania State University, University Park, PA 16802, USA 


\title{
Women's NutriBusiness Cooperatives in Kenya: An Integrated Strategy for Sustaining Rural Livelihoods
}

\author{
Audrey N. Maretzki, PhD
}

\section{ABSTRACT}

\begin{abstract}
With funding provided by the Center for Higher Education of the United States Agency for International Development, The Pennsylvania State University and Tuskegee University collaborated with the University of Nairobi in establishing women's NutriBusiness Cooperatives in the Rift Valley and Central Provinces of Kenya. Between 1992 and 1999, the cooperatives were established, facilities and equipment were supplied and extensive participatory training was provided by university-affiliated investigators and project staff. This initiative enabled approximately 2500 rural Kenyan women farmers to add value to their crops by processing and locally marketing nutritious, convenient, culturally-appropriate weaning food mixes. Implementation of the NutriBusiness model is described and challenges of cultural engagement are highlighted.
\end{abstract}

Key Words: NutriBusiness, Kenya, value-added processing, marketing, participatory training

( J Nutr Educ Behav. 2007;39:327-334)

\section{INTRODUCTION}

In much of the developing world, social progress has occurred, and living standards have risen. However, the conditions associated with human development in sub-Saharan Africa have deteriorated since 1990, and the region as a whole is unlikely to reach any of the targeted millennium development goals by 2015 . $^{1}$

In 1992, The Pennsylvania State University (PSU), in collaboration with Tuskegee University (TU) and the University of Nairobi (UoN), was competitively awarded a University Development Linkage Program (UDLP) grant by the United States Agency for International Development (USAID) to establish 2 women's nutribusiness cooperatives in Kenya. As defined by Norge Jerome, then Director of the USAID Office of Nutrition, a nutribusiness involves "activities that address nutritional needs by providing quality foods and food products at affordable prices through small-scale private sector approaches. The nutribusiness concept also incorporates environmentally regenerative production, storage and distribution techniques that

Department of Food Science, The Pennsylvania State University, University Park, Pennsylvania

Additional photos from the NutriBusiness Project accompany the on-line version of this article (available at http://www.jneb.org).

This project was funded by University Development Linkage Program Grant \#PCE 5063-A-00-2043-00 through The Center for Higher Education, U.S. Agency for International Development.

Address for correspondence: Audrey N. Maretzki, PhD, Emeritus Professor of Food Science and Nutrition, Department of Food Science, The Pennsylvania State University, University Park, PA 16802; Phone: (814) 863-4751; Fax: (814) 863-6132; E-mail: anm1@psu.edu

PUBLISHED BY ELSEVIER INC. ON BEHALF OF THE SOCIETY FOR NUTRITION EDUCATION

doi: $10.1016 /$ j.jneb.2007.08.010 avoid pollution and inappropriate or excessive use of energy and other natural resources." This article describes how rural poverty and human development issues were addressed through implementation of the nutribusiness concept in 2 rural Kenyan communities.

\section{THE NUTRIBUSINESS PROJECT Project Sites}

In 1992, the NutriBusiness Project began in 2 Kenyan sites: Bomet District in the Rift Valley Province and Murang'a District in the Central Province. The NutriBusiness Project continued through 1999. The 2 project locations, though agronomically similar, are culturally different. The residents of Bomet are primarily Kipsigis, a Nilotic culture of settled pastoralists, whereas the residents of Murang'a are mostly Kikuyu, a Bantu culture with a long agricultural history. In both areas, however, women are subsistence farmers, and many belong to 1 or more village women's self-help groups. Women's groups are organized at the village level and have successfully created small-scale entrepreneurial opportunities for many rural Kenyans. Involvement in these incomegenerating groups protects the money women earn through collective activities from appropriation by other family members. From the UoN agricultural campus, it took nearly 8 hours, on unpaved roads for the last 2 hours, to reach the Bomet site, whereas it took less than 90 minutes, largely on a paved highway, to reach the Murang'a site. Neither location had a public water supply or electricity. Climatically, the areas are quite similar. They are at comparable elevations, with seasonal rains and occasional droughts, but in most years, rainfall is adequate to produce crops without irrigation. 


\section{What Was Originally Proposed}

The original UDLP proposal included a research design that involved 4 adjacent, but politically distinct, sublocations in Bomet and the same number in Murang'a. Based on random assignment, one of the sublocations in each district was to become the site of a small-scale food processing facility, enabling shareholders from that sublocation to form a nutribusiness cooperative that would produce and regionally market a nutritious, culturally acceptable weaning food made from crops grown locally by the women on their small plots of land, called "shambas." A second sublocation would receive an intensive nutrition education program to teach local women how to prepare nutritious food for young children using locally available ingredients. In a third sublocation, the intensive nutrition education strategy would be combined with access to the cooperative's weaning food. The fourth sublocation would serve as a control.

\section{The Reality of Project Implementation}

News travels quickly in rural Kenya, and before any decision could be made about where to site the processing facilities, it became apparent that, for political and social reasons, it would not be possible to treat the sublocations differently, and furthermore, that community leaders would be very actively involved in any decision-making that involved facilities. This reality led to a decision to use existing women's groups as a basis for organizing the cooperatives.

The logic for enrolling women's groups, rather than individual women, as members of the nutribusiness cooperatives was that these groups were already engaged in projects to generate income, and therefore the members were likely to be familiar with conducting meetings, making collective decisions, and keeping fiscal records, as well as generating written minutes of their meetings. Each of the women's groups had 15 to 20 members who lived in close proximity and respected the cultural practice of decision making by the group's most senior members.

It soon became apparent that the poorest women in a village were not likely to be members of any women's group. Consequently, a decision was made to ask respected community leaders in each area to identify approximately 20 able-bodied women who they believed could not afford to join a women's group. Personal interviews were conducted with these individuals to assess their economic circumstances and their interest in being part of the NutriBusiness Project. Subsequently, a "needy" women's group was established in each area and project funds were set aside to assist the group in establishing its own income-generating project. The Murang'a group chose to raise pigs, and the Bomet group chose to raise chickens. This strategy enabled economically disadvantaged women to achieve a degree of social and economic equity with their more affluent neigh- bors and to participate as equals in the NutriBusiness Project.

\section{NutriBusiness Field Coordinators}

The NutriBusiness Project employed a field coordinator in each area who reported administratively to the UoN principal investigator (PI) through a project manager in Nairobi. On a daily basis, the field coordinators reported to the chairwoman of the board of directors for the cooperative in their assigned area. The full-time field coordinator positions were fully project-funded for 1 year, with the understanding that each cooperative would annually absorb a larger proportion of the coordinator's salary until, at the end of 5 years, the field coordinator would be employed full-time by the cooperative as the manager of its processing facility. During the early phase of the NutriBusiness Project, providing technical support and training for the "needy" women's groups was a very time- and energyintensive task for the field coordinators.

\section{NutriBusiness Project Reconceptualization}

It quickly became apparent that receiving nutrition education was much less appealing to rural Kenyan women than becoming shareholders in a cooperative business venture. Consequently, an intensely participatory strategy was initiated to enable the women farmers in each of the project sublocations to add economic value to the crops they grew on their shambas by processing and marketing a weaning food that could improve the nutrition of their own children and increase the availability of convenient, affordable, culturally appropriate weaning food in regional peri-urban markets. By directly linking the development of women's agribusiness knowledge and skills to the improved health of children, the project addressed the interrelated issues of poverty and human development by building multiple forms of capital (social, financial, human, physical, and natural $)^{3}$ in these rural Kenyan communities, using women's intimate connections with food and family as the medium through which to promote development.

What was conceived as a community research and development project was rapidly transformed into a participatory learning initiative for both university investigators and rural community residents. Early in the life of the project, it was hypothesized that if the nutribusiness model could be successfully implemented in Bomet, an area isolated from the market economy of Nairobi and with a population that was poorly educated, it could be replicated by women in many other rural Kenyan communities. Conversely, if the nutribusiness model was found to be unworkable by women in Murang'a, who were more educated and familiar with the way businesses operate in an urban metropolis, it was not likely to succeed elsewhere. As a result, the decision was made to provide similar project facilities and training in Bomet and Murang'a and to observe the 
respective strategies used by the women for making decisions, managing resources, capitalizing on opportunities, overcoming obstacles, and moving toward the goal of establishing a sustainable business venture.

\section{Initial Activities in the Communities}

An early project activity was exchange visits between women leaders from Bomet and Murang'a. This exchange helped to establish a shared identity with the NutriBusiness Project and created strong bonds of friendship between women from ethnic groups that were at times rivals in the heated Kenyan political climate of the early 90s. The visits had the added effect of promoting friendly competition between the 2 cooperatives.

The exchange visits were followed by field trips to Bomet and Murang'a by a multidisciplinary faculty team from the participating universities. The purpose of these faculty visits was to conduct an informal participatory rural community appraisal focused on household composition; child and community health; economic and social activities of women's groups; local activities of governmental, religious, and civil society organizations; specific activities engaged in, and decisions made by, adult men and women, youth, and the elderly; child rearing and feeding practices; crop and animal production, household use, and sales; and household food acquisition, preparation, and consumption practices. During these visits, women were observed as they prepared food for, and fed, their young children. Samples of these locally prepared children's food items were collected for nutrient analysis in the UoN food science laboratories. ${ }^{4}$ The information gathered in the field became the basis for future community workshops.

\section{Participatory Workshops in the Communities}

Several months after the rural appraisal was undertaken, a 3 -day workshop was conducted in each area. For this workshop, laboratory-generated information on the nutrients in a typical serving of each locally prepared infant food item was shown as a bar graph that compared the food item with a young child's daily nutrient needs. The bar graphs represented the nutritional quality of traditional weaning food items the women themselves had prepared, and the information was accessible even to those who were illiterate. What distinguished this activity from a typical nutrition education lesson was that the women were members of a cooperative that was embarking on the development, production, and eventual marketing of a weaning food product. By the end of the presentation, the nutritional superiority of traditional mixed dishes over the popular weaning gruel (uji) containing only a single grain had been clearly illustrated.

The next phase of the 3-day workshop involved the assignment of participants to teams made up of several individuals from each of the participating subdivisions in the area. The task of each team was to "prepare a good food for a young child" from crops that were grown on their shambas. In preparation for this activity, the field coordinators secured grains as well as other indigenous and exotic food items that were grown locally. For each of these items, a colorful nutrient bar graph was created on a large sheet of newsprint. The graphs were grouped into grains, dried beans, leafy green and yellow vegetables, and "other" vegetables, fruits, and tubers. The actual food item was placed on the newsprint beside its graphic representation. After viewing the display of ingredients, each team selected what they would like to use in their cooperative's weaning food product (Figure 1). Equipped with a knife and a single cooking pot placed on 3 stones over an open fire, they cooked their dish for all the workshop participants to sample. An animated critique of each dish followed the tasting. Without the provision of specific instructions on how to make nutritional decisions, each group had combined 1 or 2 grains, beans, a leafy green, and 1 or more "other" items. By the conclusion of the cooking, tasting, and critiquing process, the group had identified the key ingredients to be included in their weaning food product. In Bomet the key ingredients were finger millet, maize, beans, pumpkin, and pumpkin leaves. In Murang'a the key ingredients were bananas, maize, beans, carrots, and amaranthus leaves.

For the second cooking activity, teams were structured by sublocation. This time each team was instructed to prepare a dish combining all of the key ingredients, but the amount of each ingredient and how the dish would be prepared was left to the discretion of the group. An observer/recorder was assigned to each group to record the amount of each ingredient used and how the dish was prepared. Aliquots of the finished products were packaged for transport to the UoN for analysis, after which the products were sampled and evaluated for taste, smell, texture, and consistency by the participants.

On the final day of the workshop, the participants were divided into 2 teams, and individuals from the sublocation that had prepared the best-liked product on the previous

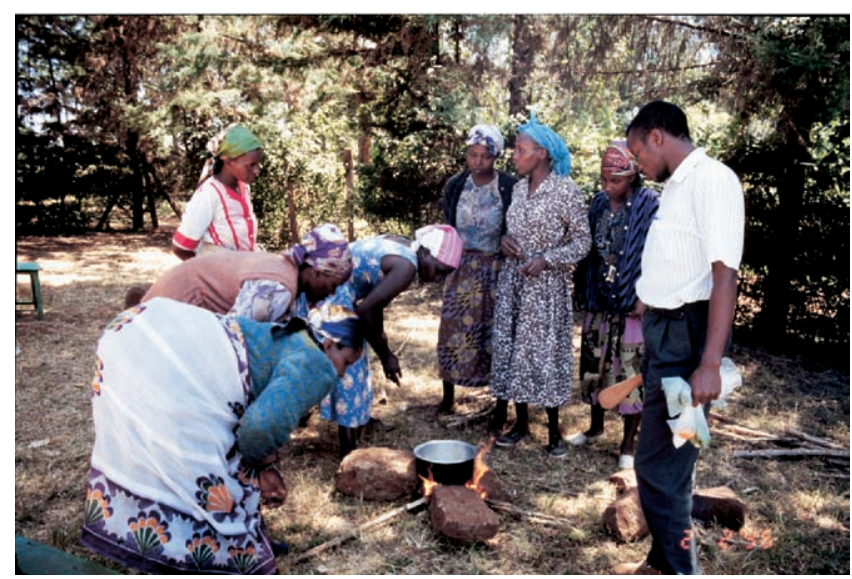

Figure 1. NutriBusiness workshop participants prepare their group's "good food for a young child." 
day provided "expert" instructions on how the dish should be prepared. The final products were sampled and critiqued by all the workshop participants before being served to a number of village children between 6 months and 3 years of age who were brought to the workshop site by their mothers. The workshop participants anxiously watched as each mother first tasted the 2 samples in random order and then fed them to her child. Participants who were able to write, carefully recorded the reactions of the mothers and their children. After the mothers and children departed, the discussion was particularly lively. The women had come to recognize that these tasters were their potential consumers whose acceptance or rejection would spell the success or failure of their entrepreneurial venture into the world of food processing and marketing.

\section{Nutritional Optimization and Shelf-life Testing}

Knowing the proportionate amount of each key ingredient in the weaning food items prepared in the workshops enabled project nutritionists to use African food composition tables ${ }^{5}$ to calculate the approximate nutritional composition of each product and to adjust the formulations to meet, as closely as possible, the Codex Alimentarius standards for a supplemental, cereal-based food item for older infants and young children. ${ }^{6}$ None of the key ingredients was eliminated from either Tupcho (which translates as 'working together'), the name given by the Bomet women to their weaning food product, or from BASCOT (a novel word incorporating the first letter in the name of each ingredient in the Murang'a product). Both of the optimized formulations, however, included carrots and/or pumpkin marrow and pumpkin leaves and/or amaranthus leaves. These modifications allowed each group some opportunity for seasonal ingredient substitution without affecting the nutritional composition of their product.

After the weaning food formulations had been optimized, both the Bomet and Murang'a products were processed in the food science laboratory at the UoN in sufficient quantity to conduct accelerated shelf-life studies. These studies indicated that the dry weaning food mixes could be stored in sealed plastic bags for up to a year at ambient Kenyan temperatures. A sufficient amount of the Bomet formulation was also processed to conduct a controlled feeding trial.

\section{Preparing Optimized Formulas in the Communities}

The individual ingredients for each mix were processed, dried, and milled into flours in the university laboratory. These flours and the combined mixes were subsequently used in sublocational workshops held in each area (Figure 2). In these workshops, representatives from the participating women's groups first prepared their optimized product

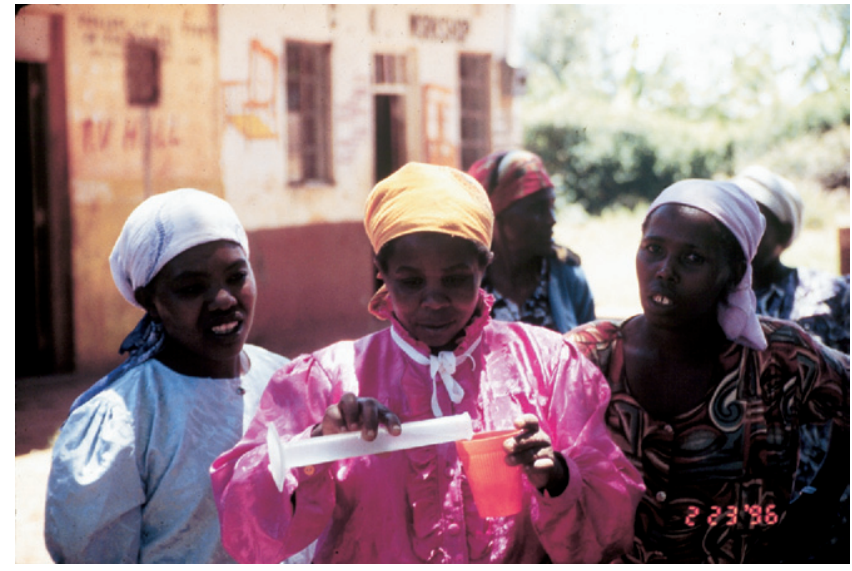

Figure 2. NutriBusiness workshop participants learn the importance of accurately measuring the amount of liquid to be used in preparing their Nutri-Mix product.

from fresh ingredients and then created their dry mix by weighing out and mixing the separate flours in the correct proportion and cooking the product according to preparation instructions that would appear on the package. When they compared their weaning food prepared from raw ingredients and from a dry mix, the women clearly understood that their Nutri-Mix (as the products were eventually labeled) was nutritionally superior to the uji that most weaning-age children in Kenya were receiving. The representative from each participating women's group left this workshop with a packet of their Nutri-Mix and written instructions they were to follow in preparing the product for all the members of their group to sample. This preliminary product distribution to about 80 women's groups was the first opportunity for the approximately 2500 women who were associated with the Kenya NutriBusiness Project to actually see and taste the products they had been hearing about for several years.

\section{Organizing the NutriBusiness Cooperatives}

Organizational development training was conducted in each area to illustrate how the nutribusiness cooperative would be structured. Subsequently, a full-day meeting was organized at a local hotel to select the executive committee for each cooperative. The organizational workshops involved the designated representatives and alternates from participating women's groups and were held in each of the 4 project sublocations in Bomet and in the 3 Murang'a sublocations. The number of participating women's groups varied by sublocation from 5 to 15 . At these workshops, the responsibilities of the nutribusiness representatives, alternates, and officers were discussed. Subsequently, each sublocation elected its own nutribusiness officers from among the designated women's group representatives in attendance. Following local custom for the number of officers elected by a women's group, the Tupcho NutriBusiness Cooperative in Bomet had 16 members on its board of 
directors, and the Murang'a NutriBusiness Cooperative had 9.

\section{Cooperative Management and Leadership}

Once the nutribusiness boards of directors in Bomet and Murang'a had duly elected their officers, the project manager began the process of registering the cooperatives with the Kenyan Ministry of Cooperatives (MOC). Subsequently, the 2 boards were brought together in Nairobi for 3 days of intensive, hands-on cooperative management and leadership training. The training was conducted in English, with translation into KiSwahili as well as into Kikuyu and Kipsigis, as necessary, to accommodate the language skills of all participants. The field coordinators, who took an active part in planning and conducting the training, were expected to assist their board members in providing follow-up training for the cooperative members in each location. It was also expected that, once the cooperatives were officially registered with the MOC, additional training as well as monitoring and oversight of financial records would be provided by $\mathrm{MOC}$ officials assigned to the Bomet and Murang'a district offices. This expectation was not fulfilled, and eventually the project was obliged to contract with a nongovernmental organization to review the records of one of the cooperatives and provide both the project staff and the cooperative itself with an independent assessment of the various financial and other record-keeping systems that needed to be in place to achieve the desired level of transparency.

\section{Product Marketing}

A challenging part of establishing a nutribusiness was to effectively engage the cooperative's rural shareholders in the marketing of their value-added food product. Rural Kenyan women were accustomed to selling their agricultural produce in local markets, where the price fluctuates seasonally with supply. They were also familiar with selling a commodity such as maize to a government marketing board or selling milk to a national dairy cooperative. However, the task of selling a multi-ingredient, shelf-stable convenience item with a unique nutritional profile designed for a specific market segment was a totally new concept to them. Preparing members of the cooperative to make rational decisions about marketing such a product required innovative training that took place repeatedly during the project.

Marketing workshops were conducted for members of the board of directors and other shareholders from each cooperative. Role playing and a variety of hands-on activities were employed to illustrate the importance of the 3Ps (product, placement, and pricing) to the success of their enterprise. The need for product quality assurance, through the application of simplified hazard analysis and critical control point (HAACP) methods, as well as the impor- tance of worker supervision and inventory management to prevent pilferage, were addressed. The need for planned sourcing of raw ingredients, accurate weighing and measuring, appropriate product labeling and dating, protective packaging, care in the storage and handling of ingredients and safety precautions that needed to be taken at each stage in the product processing, as well as distribution issues, were also addressed in these sessions. Eventually, each cooperative arrived at a wholesale as well as a retail price for its Nutri-Mix product that reflected a reasonable projection of its ongoing business costs and anticipated sales volume. Shareholders in the cooperatives, as well as receiving payment for the raw ingredients they provided, had an expectation that they would annually share in any distribution of the cooperative's profits. In addition, members were able to purchase the Nutri-Mix at the wholesale price, either for their home use or for resale at the retail price in their community. This marketing strategy was popular with the shareholders.

\section{Facilities and Staffing}

The NutriBusiness Project funded construction of the facility for each cooperative and purchased the essential processing equipment. A small truck with a capped bed was also supplied to each cooperative. The trucks were fitted with bench seats for transporting people, but their main use was for transporting raw ingredients and fuel for the hammer mill and dehuller with which each facility was equipped. The project vehicles were badly abused by their male drivers, who used them for various types of for-hire transport. Costly vehicle repairs were soon needed, and the cooperatives' members learned that owning a vehicle could be a liability as well as a convenience and a very visible status symbol.

Each of the cooperatives employed a young man to operate its hammer mill and grain dehuller. In addition to producing the various flours for the weaning food mixes, these pieces of equipment were operated on a fee-forservice basis to process grains for home use. Milling and dehulling fees were paid either in cash or as a portion of the grain to be milled. Profits to the cooperatives derived from the milling and dehulling operations included the sale of accumulated grain as well as the sale of by-products, which were used for animal feed. The mills also served as popular meeting places for residents of the village, and the prestige associated with their ownership was very important to the women.

\section{Solar Dryers}

The most technically challenging element in the processing of the Nutri-Mixes was the design and construction of a solar dryer capable of handling the year-round drying of cooked beans quickly enough to prevent the growth of mold and mold toxins (such as aflatoxin) during the sea- 
sonal rains. After determining that the solar dryers being marketed and used in Kenya at the time were not adequate, the task of designing a dryer for the NutriBusiness Project was undertaken locally. A design was created for a solar dryer equipped with solar panels and a storage battery. This system stored enough energy during daylight hours to power a fan that significantly increased air circulation in the drying chamber and permitted drying to continue after sunset by pulling heat into the drying chamber from the base of crushed rocks on which the dryer was constructed. The solar battery also permitted the use of a mechanical device to securely seal the plastic bags in which the NutriMix was packaged for retail sale. This dryer design allowed a single layer of cooked beans spread on 24 wire mesh trays, each measuring 3 feet by 3 feet, to dry in approximately 9 hours. Drying the other ingredients for the mixes required considerably less time and posed fewer safety risks. The solar dryers designed for the NutriBusiness Project were fabricated by the Nairobi-based Kenya Industrial Research Development Institute (KIRDI) and transported by truck to the processing sites.

Other specialized food processing equipment was also designed for use at the rural nutribusiness sites and fabricated by skilled Kenyan "jua kalis," small, independent metal and wood crafters, who were grateful for the business the project provided.

Additional studies were undertaken through the NutriBusiness Project to develop a unique animal-source food product that could be safely processed under the drying conditions obtained in the project's solar dryer. ${ }^{7,8}$ This dried product, called a "Chiparoo," combined rabbit or chicken meat with white or sweet potatoes to produce a crispy, shelf-stable product that could be crumbled into cooked porridge for infants or eaten as a snack by older children. ${ }^{9}$ Chiparoos were successfully taste-tested in a rural Kenyan community, but project funding terminated before their production could be integrated into the nutribusiness operations.

\section{Product Processing Workshop}

After the first dryer was installed in Bomet, a 3-day processing workshop was conducted, to which the field coordinator, the board of directors, and other members from the Murang'a NutriBusiness Cooperative were invited. During this workshop the participants were taken through every step of the Nutri-Mix production process, from receiving the raw materials through packaging and dating of the finished product. In the nutribusiness operation, most raw ingredients are delivered to the processing site by cooperative members, who receive immediate payment. This is an important consideration for women who have very little cash available. After being received, perishable commodities (bananas, pumpkins, carrots, amaranthus, and pumpkin leaves) are cleaned and sliced as needed and then blanched prior to drying to preserve color and nutrients. Beans are soaked and their external hulls removed prior to being boiled for 45 minutes to inactivate antinutrient factors. Maize is dehulled in a domestically fabricated dehuller to reduce its fiber content before milling. Finger millet is soaked and deglumed prior to drying. This process of removing the millet hull increases shelf life and decreases fiber. After drying and subsequent milling, each ingredient is stored separately in large, tightly covered plastic bins until the porridge mix is prepared. The process of weighing and mixing the separate flours to achieve a consistent product was demonstrated during the processing workshop, as was a packing, sealing, and labeling process that assured that each bag of Nutri-Mix contained 500 grams of porridge mix and carried the date on which the mix was packed. The retail price of Nutri-Mix in 2000 was approximately $\$ 1.00$ (US) per package.

\section{Evaluating the Porridge Mixes}

The principal difference between the Bomet and Murang'a formulations was that the Bomet product contained finger millet, an ingredient that Kipsigis women have traditionally considered to be the most important weaning food for young children, whereas the Murang'a product contained bananas, a fruit widely grown in the central region and used both fresh and dried in preparing traditional Kikuyu weaning food items. Both the Bomet and Murang'a products contained maize as an inexpensive energy source, beans as a source of protein, and carrots or pumpkin marrow and amaranthus or pumpkin leaves as alternative sources of provitamin A. A sample of the dry porridge mix from each location was sent to an independent laboratory in the United States for nutrient analysis. This information was used to create a nutrient label, reviewed and approved by the Kenya Department of Health, for each product. Though few of the women in either group were initially aware of nutrition labels, they were insistent that their weaning food's label should include nutrition information as well as the required ingredient listing and preparation and storage instructions. They also agreed to include on the label a statement that this product was appropriate as a supplemental food for children 4-6 months or older and that it was not a substitute for breast milk.

After the product formulations were established, a controlled feeding trial was conducted in a rural nutrition rehabilitation center. The children received either the institution's normal cereal-based gruel or the Bomet porridge mix for 6 weeks. Weight gain and hemoglobin status were monitored. Children receiving the Tupcho Nutri-Mix showed improved iron status and a greater weight gain when compared with children who received the rehabilitation center's regular diet. ${ }^{10}$ The cost of conducting a similar study using the Murang'a formulation was beyond the scope of the project budget. However, the comparable nutrient composition of the 2 Nutri-Mix formulations sug- 
gested that the Murang'a product would produce similar results.

\section{DISCUSSION Problems Encountered}

After receiving initial training and technical assistance on the use of its dryer, the Bomet cooperative began processing the Tupcho Nutri-Mix and was very successful in selling it in local villages. Members were elated when the Tupcho NutriBusiness Cooperative received an award of distinction in a regional small-business exhibition. Within a short time, however, the cooperative's manager, a single mother with several school-aged children, succumbed to acquired immunodeficiency syndrome (AIDS), and the very popular field coordinator left the project. Shortly before the cooperative was forced to deal with these problems, the UoN PI died unexpectedly, and the women in Bomet were left without the professional and personal support of a highly respected member of their ethnic group. Although the UoN agreed to continue its technical assistance to the Bomet cooperative, regular visits to the distant Rift Valley were difficult to schedule, and the alternative arrangements that were made to provide support on an as-needed basis were hampered by poor communications between the field and the UoN campus. When a broken part for their solar dryer was taken to Nairobi for repair and not returned, it meant that the cooperative could no longer process its porridge mix. Given the reality of their situation, the Bomet women decided to use their mill and dehuller to process maize and millet on a fee-for-service basis, and they transformed their building into a facility for storing grain that they bought and sold locally when the seasonal price was favorable.

In contrast to Bomet, the Murang'a NutriBusiness Cooperative received continuing technical and marketing support from the UoN and, after the UDLP project ended, was able to market its Bascot Nutri-Mix to local health centers as well as to individual consumers in the area. The capacity of its processing facility was not reached, however, before a severe drought in Central Kenya temporarily halted production of the porridge mix. The drought forced the cooperative to rely solely on revenue generated by fee-forservice milling and dehulling of grain until members were once again able to provide sufficient raw ingredients to resume production of their BASCOT Nutri-Mix.

In 2005, Touchstone Consultant Services, a marketing firm with close connections to the UoN's College of Agriculture, approached the Murang'a NutriBusiness Cooperative with a proposal to reinvigorate its product marketing by renaming the product, redesigning the packaging, and repositioning the product as a nutritional food supplement rather than as a weaning food. The marketing strategy employed was to target the 2 national supermarket chains in Kenya as well as health centers, schools, and organizations involved in the provision of food supplements to persons with AIDS and other conditions requiring nutri- tional support. A business plan has recently been developed to expand marketing and technical services to the Murang'a NutriBusiness Cooperative and possibly to the Tupcho NutriBusiness Cooperative in Bomet, as well (written communication with Anne Tei Mukunya, March 2, 2007). Touchstone consultants will also provide services to 2 additional nutribusiness projects that were developed between 2001 and 2005 in Kenya's Eastern Province with financial support from the United States Agency for International Development's program in Kenya (USAID/ Kenya). These nutribusiness sites, like Murang'a, are communities that are accessible to urban markets, and through their proximity to, and connections with, the university, they should be able to receive technical support not only from UoN, but also from the Kenya Agricultural Research Institute.

\section{IMPLICATIONS FOR RESEARCH AND PRACTICE}

The relevance of the nutribusiness concept is as a comprehensive, local development strategy targeting women. In rural African communities, change occurs at a pace that reflects the dynamic interplay between indigenous and external knowledge systems. Institutional change agents have initiated a wide range of evidence-based outreach programs to address the plethora of problems standing in the way of the achievement of national development goals in rural Africa. However, these change agents often fail to perceive the importance of creating an opportunity for communities' indigenous knowledge systems to effectively meld with the Western ways of knowing that are embraced by the change agents. ${ }^{11}$ Hassel has termed the process of interaction between academic scientists and indigenous people "crosscultural engagement," where the cultures to be crossed are those of indigenous communities on one hand and the community of Western science on the other. ${ }^{12}$

In the NutriBusiness model, rural women's traditional knowledge and skills are valued and integrated with a local development strategy, through which they gain and apply new knowledge and skills while developing confidence in their ability to collectively make decisions and accept the consequences of these decisions. At their own pace, and in their own cultural and ecological reality, nearly 2500 women in 2 Kenyan communities were "engaged" with change agents and with the novel nutribusiness concept of processing and marketing unique food products that are convenient, healthful, and appropriate to their culture. These women appear to be confident that their cooperative initiative and effort will, over time, enable them to not only "do good" for others but also "do well" for themselves. The Kenya NutriBusiness Project is an example of change that has occurred because the unique cultures of campus and community are effectively engaged in activities to simultaneously reduce poverty and promote human development. 


\section{ACKNOWLEDGMENT}

This project was funded by University Development Linkage Program Grant \#PCE 5063-A-00-2043-00 through The Center for Higher Education, U.S. Agency for International Development.

\section{SUPPLEMENTARY DATA}

Additional photos from the NutriBusiness Project accompany the on-line version of this article (available at http://www.jneb.org).

\section{REFERENCES}

1. United Nations Development Program. Human Development Report 2005: International cooperation at a crossroads. Aid, trade, and security in an unequal world. New York: United Nations Development Program; 2006.

2. Jerome N. Nutribusiness. FrontLines, Washington, DC: U.S. Agency for International Development; 1991: p. 1.

3. Scoones I. Sustainable rural livelihoods: A framework for analysis. Institute for Development Studies Working Paper \#72. Available at: http://www.ids.ac.uk/ids/bookshop/wp/wp72.pdf. Accessed April 13, 2007.
4. Muroki N, Maritim G, Karuri E, et al. Involving rural Kenyan women in the development of nutritionally-improved weaning foods. J Nutr Educ. 1997;29:335-342.

5. U.S. Department of Health, Education and Welfare and Food and Agriculture Organization. Food Composition Tables for Use in Africa. Washington, DC: U.S. Department of Health, Education and Welfare and Food and Agriculture Organization; 1968.

6. FAO/World Health Organization. Codex Alimentarius. Standard for processed cereal-based food for infants and young children. Codex Alimentarius STAN 74 Vol. 4: 1981.

7. Kieras SJ. Safety assessment and sensory analysis of a meat-based dried snack food for children in sub-Saharan Africa [master's thesis]. University Park, Pa: Pennsylvania State University; 1999.

8. Kieras S, Mills EW, Knabel S, Maretzki AN. Validation of pathogen destruction during manufacture of a meat-based potato snack (Chiparoo). J Food Proc Pres. 2003;26:385-399.

9. Maretzki AN, Mills EW. Applying a NutriBusiness approach to increase animal source food consumption in local communities. J Nutr. 2003;133:4031S-4035S.

10. Kulwa K. Effect of Tupcho mixed porridge on the nutrition of malnourished children (6-36 months) in an urban slum, Kibera, Nairobi [master's thesis]. Nairobi, Kenya: Applied Nutrition Program, University of Nairobi; 2000.

11. Semali LM, Maretzki AN. Valuing indigenous knowledge: Strategies for engaging communities and transforming the academy. Journal of Higher Education Outreach and Engagement. 2005:10:89-106.

12. Hassel CA. The craft of cross-cultural engagement. Journal of Extension. 2005;43:6.6FEA1. Available at: http://www.joe.org/joe/2005december/ a1.shtml. Accessed April 13, 2007. 